\title{
Improving interinstitutional and intertechnology consistency of pulmonary SBRT by dose prescription to the mean internal target volume dose
}

\author{
L. Wilke' (D) - C. Moustakis ${ }^{26} \cdot$ O. Blanck ${ }^{2}$. D. Albers ${ }^{28} \cdot$ C. Albrecht ${ }^{3} \cdot$ Y. Avcu $^{4} \cdot$ R. Boucenna $\cdot$ K. Buchauer $^{6}$. \\ T. Etzelstorfer ${ }^{7}$. C. Henkenberens ${ }^{8}$ - D. Jeller ${ }^{9}$. K. Jurianz ${ }^{10}$. C. Kornhuber ${ }^{11}$ - M. Kretschmer ${ }^{27} \cdot$ S. Lotze ${ }^{12}$. \\ K. Meier ${ }^{13}$ • P. Pemler ${ }^{14}$ - A. Riegler ${ }^{15}$ - A. Röser ${ }^{16}$ • D. Schmidhalter ${ }^{17,18} \cdot$ K. H. Spruijt ${ }^{19}$ • G. Surber ${ }^{20}$ • V. Vallet ${ }^{21}$. \\ R. Wiehle ${ }^{22} \cdot$ J. Willner ${ }^{23} \cdot$ P. Winkler ${ }^{24} \cdot$ A. Wittig ${ }^{25} \cdot$ M. Guckenberger ${ }^{1} \cdot$ S. Tanadini-Lang ${ }^{1}$
}

Received: 13 May 2020 / Accepted: 10 May 2021 / Published online: 1 July 2021

(c) The Author(s) 2021

\begin{abstract}
Purpose Dose, fractionation, normalization and the dose profile inside the target volume vary substantially in pulmonary stereotactic body radiotherapy (SBRT) between different institutions and SBRT technologies. Published planning studies have shown large variations of the mean dose in planning target volume (PTV) and gross tumor volume (GTV) or internal target volume (ITV) when dose prescription is performed to the PTV covering isodose. This planning study investigated whether dose prescription to the mean dose of the ITV improves consistency in pulmonary SBRT dose distributions.
\end{abstract}

$\triangle$ L. Wilke

lotte.wilke@usz.ch

1 Klinik für Radio-Onkologie, Universitätsspital Zürich, Zürich, Switzerland

2 Klinik für Strahlentherapie, Universitätsklinikum Schleswig-Holstein - Campus Kiel, Kiel, Germany

3 CyberKnife Centrum Süd, Schwarzwald-Baar Klinikum Villingen-Schwenningen, Villingen-Schwenningen, Germany

4 Klinik für Strahlentherapie und Radioonkologie, Universitätsspital Basel, Basel, Switzerland

5 Institut de radio-oncologie, Hislanden Lausanne, Lausanne, Switzerland

6 Klinik für Radio-Onkologie, Kantonsspital St. Gallen, St. Gallen, Switzerland

7 Radio-Onkologie, Ordensklinikum Linz Barmherzige Schwestern, Linz, Austria

8 Klinik für Strahlentherapie und Spezielle Onkologie, Medizinische Hochschule Hannover, Hannover, Germany

9 Radio-Onkologie, Kantonsspital Luzern, Luzern, Switzerland

10 MVZ Gamma-Knife Zentrum Krefeld, Krefeld, Germany

11 Klinik für Strahlentherapie, Universitätsklinikum Halle, Halle, Germany

12 Klinik für Radioonkologie und Strahlentherapie, Uniklinik RWTH Aachen, Aachen, Germany

13 Strahlentherapie, Klinikum Wolfsburg, Wolfsburg, Germany

14 Klinik für Radioonkologie, Stadtspital Triemli, Zürich, Switzerland
15 Institut für Radioonkologie und Strahlentherapie, Landesklinikum Wiener Neustadt, Wiener Neustadt, Austria

16 Strahlentherapie und Radio-Onkologie, Helios Universitätsklinikum Wuppertal, Wuppertal, Germany

17 Division of Medical Radiation Physics and Department of Radiation Oncology, Inselspital, Bern, Switzerland

18 University Hospital, and University of Bern, Bern, Switzerland

19 Institut de radio-oncologie, Clinique des Grangettes, Geneva, Switzerland

20 Institut für Radiochirurgie und Präzisionsbestrahlung, CyberKnife Centrum Mitteldeutschland, Erfurt, Germany

21 Service de radio-oncologie, Centre hospitalier universitaire vaudois, Lausanne, Switzerland

22 Klinik für Strahlenheilkunde, Universitätsklinikum Freiburg, Freiburg, Germany

23 Klinik für Strahlentherapie, Klinikum Bayreuth, Bayreuth, Germany

24 Universitätsklinik für Strahlentherapie-Radioonkologie, LKH-Univ. Klinikum Graz, Graz, Austria

25 Departent of Radiotherapy and Radiation Oncology, University Hospital Jena, Friedrich-Schiller-University Jena, Jena, Germany

26 Klinik für Strahlentherapie, Universitätsklinikum Münster, Münster, Germany

27 Radiologische Allianz Hamburg, Hamburg, Germany

28 Klinik für Strahlentherapie und Radioonkologie, Universtitätsklinikum Hamburg-Eppendorf, Hamburg, Germany 
Materials and methods This was a multi-institutional planning study by the German Society of Radiation Oncology (DEGRO) working group Radiosurgery and Stereotactic Radiotherapy. CT images and structures of ITV, PTV and all relevant organs at risk (OAR) for two patients with early stage non-small cell lung cancer (NSCLC) were distributed to all participating institutions. Each institute created a treatment plan with the technique commonly used in the institute for lung SBRT. The specified dose fractionation was $3 \times 21.5 \mathrm{~Gy}$ normalized to the mean ITV dose. Additional dose objectives for target volumes and OAR were provided.

Results In all, 52 plans from 25 institutions were included in this analysis: 8 robotic radiosurgery (RRS), 34 intensitymodulated (MOD), and 10 3D-conformal (3D) radiation therapy plans. The distribution of the mean dose in the PTV did not differ significantly between the two patients (median $56.9 \mathrm{~Gy}$ vs $56.6 \mathrm{~Gy}$ ). There was only a small difference between the techniques, with RRS having the lowest mean PTV dose with a median of $55.9 \mathrm{~Gy}$ followed by MOD plans with $56.7 \mathrm{~Gy}$ and 3D plans with 57.4 Gy having the highest. For the different organs at risk no significant difference between the techniques could be found.

Conclusions This planning study pointed out that multiparameter dose prescription including normalization on the mean ITV dose in combination with detailed objectives for the PTV and ITV achieve consistent dose distributions for peripheral lung tumors in combination with an ITV concept between different delivery techniques and across institutions.

Keywords Stereotactic radiation therapy · Lung cancer · Organs at risk · Planning benchmark study · Quality assurance · Dose prescription

\section{Introduction}

Lung cancer is responsible for the highest number of cancer deaths in males and females worldwide. Surgical resection is standard of care, but growing numbers of patients are medically inoperable due to their age and comorbidities. In patients with untreated early stage non-small cell lung cancer (NSCLC) the median survival is 13 months and the 5 -year cancer-specific survival rate is $16 \%$ [1]. In these patients, being inoperable or refusing surgery, the standard of care is stereotactic body radiation therapy (SBRT) [2-5]. Furthermore, SBRT is increasingly applied for patients with lung metastases in the oligometastatic disease [6-12].

Despite the fact that the use of SBRT is rapidly increasing, there is high variability in prescribed doses and normalization methods between prospective trials, between institutions and even between practice guidelines, which makes it difficult to compare the truly delivered dose and the treatment outcome between institutions. A recent multicenter planning study from Giglioli et al. [13] showed that the general equivalent uniform planning target volume (PTV) dose varied between 105 and162Gy if only the dose per fraction was specified without further specification on the dose prescription and normalization method, the dose inhomogeneity and PTV constraints.

Historically an inhomogeneous dose was prescribed to a certain PTV encompassing isodose line, normalization was done on the maximum dose or a representative dose point inside the target volume. This is in agreement with the International Commission on Radiation Units and Measurements (ICRU) reports 50 and 62 [14, 15] which recommend prescription and normalization on a representative point. ICRU 83 [16] for modulated treatment planning recommends dose prescription to the median PTV dose instead of prescribing and reporting the dose to a single point. The new ICRU report 91 [17] recommends for stereotactic treatments to prescribe the dose to the isodose surface that covers an optimal percentage of the PTV. Additionally, it is recommended that the prescription does not only specify the prescribed dose and the normalization method but a comprehensive set of accepted values for target coverage and organ at risk doses. A recent multi-enter planning study from the German Society of Radiation Oncology (DEGRO) working group for Radiosurgery and Stereotactic Radiotherapy [18] showed that interinstitutional variation in the mean PTV dose was reduced by specifying the dose as well as the prescription method; the prescribed dose of $3 \times 15 \mathrm{~Gy}$ had to cover $95 \%$ of the PTV and the allowed D2\% was set to $69.2 \mathrm{~Gy}$. However, the variability was still $>22 \%$, and there was a large difference between the SBRT techniques. Similarly, all other dosimetric parameters characterizing gross tumor volume (GTV) and PTV dose showed large differences.

Based on the European Society for Radiotherapy and Oncology (ESTRO) and Advisory Committee on Radiation Oncology Practice (ACROP) consensus guidelines for SBRT of peripherally located NSCLC [19], de Jong et al. published recommendations for prescribing and recording taking the ICRU report 91 into account [20]. They showed that even between 8 centers having long-term clinical experience with SBRT significant differences can be seen in the actual planned dose to the PTVs and GTVs.

There is strong retrospective data indicating that this variation in GTV and PTV doses is of clinical relevance. Several studies reported that local tumor control after pulmonary SBRT was significantly associated with the biolog- 
Table 1 The different objectives for the treatment planning. Minor deviations were allowed in the order of the objectives in the table

\begin{tabular}{lll}
\hline & Objective & Allowed deviation \\
\hline PTV coverage & D95\%>70\% & D90\%>70\% \\
& $\left(=45.2 \mathrm{~Gy}, \mathrm{BED}=112 \mathrm{~Gy}_{10}\right)$ & $\left(=45.2 \mathrm{~Gy}, \mathrm{BED}=112 \mathrm{~Gy}_{10}\right)$ \\
ITV coverage & $\mathrm{D} 95 \%>90 \%$ & $\mathrm{D} 90 \%>90 \%$ \\
& $\left(=58.1 \mathrm{~Gy}, \mathrm{BED}=170 \mathrm{~Gy}_{10}\right)$ & $(=58.1 \mathrm{~Gy}, \mathrm{BED}=170 \mathrm{~Gy} 10)$ \\
$\mathrm{CI}_{\mathrm{RTOG}}=\mathrm{V} 70 \% / \mathrm{V}(\mathrm{PTV})$ & $<1.20$ & $<1.25$ \\
$\mathrm{D} 0.1 \mathrm{ml}$ & $<107 \%$ & $<110 \%$ \\
& $\left(=69 \mathrm{~Gy}, \mathrm{BED}=228 \mathrm{~Gy}_{10}\right)$ & $(=71 \mathrm{~Gy}, \mathrm{BED}=239 \mathrm{~Gy} 10)$ \\
\hline
\end{tabular}

$P T V$ planning taget volume, $D 95 \%$ dose to $95 \%$ of the volume, BED biologically effective dose, ITV internal target volume, CIRTOG Radiation Therapy Oncology Group conformity index, $V 70 \%$ volume recieving $70 \%$ of the prescribed dose, $V(P T V)$ volume of the planning target volume

ically effective dose (BED) at the isocenter and the mean GTV dose [21-23]. There is consequently a clinical need to better standardize the planning of pulmonary SBRT and to reduce interinstitutional variability. As basis for this study, we postulate a multiparameter dose prescription including dose normalization to the mean ITV dose in combination with specification of more detailed PTV and ITV objectives reduces the interinstitutional variation in ITV and PTV dose.

\section{Materials and methods}

\section{Dataset}

This study was conducted in the DEGRO working group Radiosurgery and Stereotactic Radiotherapy. The same two patients as in the work of Moustakis et al. [18] with inoperable early stage NSCLC were selected for this study to allow comparison with previous results (Fig. 1). Since the patients were anonymized and from a previous investigation, no ethics approval was needed. Patient 1 had a peripheral lesion in the left upper lobe and patient 2 had a peripheral lesion in the right lower lobe. Contouring of the GTV was performed in the lung window and an internal target volume (ITV) was generated as the encompassing of all tumor positions based on a four dimensional (4D) computed tomography (CT). An ITV to planning target volume (PTV) margin $5 \mathrm{~mm}$ was applied resulting in PTV sizes of $23.8 \mathrm{~cm}^{3}$ and $19.4 \mathrm{~cm}^{3}$, respectively. Ipsi- and contralateral lung, the chest wall, spinal cord and esophagus were delineated as organs-at-risk (OAR) for both patients.

CT images and structures of ITV, PTV and all relevant OARs for these two patients were sent to 27 participating institutions, all having experience in pulmonary SBRT. Each institute was asked to create a treatment plan with the technique commonly used in the institute for lung SBRT, and to follow the dose prescription as described below.
Fig. 1 Axial and coronal CT slices with structures of the two patients used for this planning study
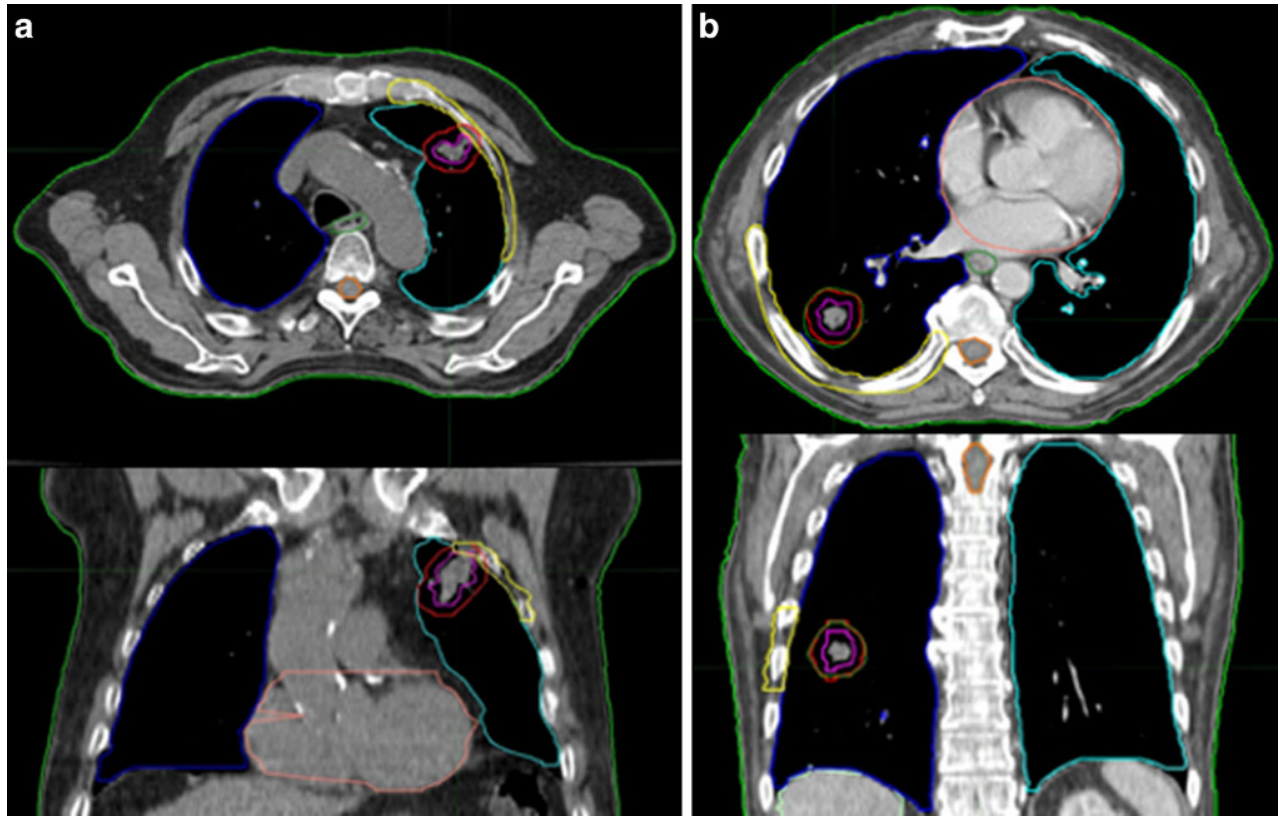


\section{Dose prescription}

The multiparameter dose prescription included a normalization of $3 \times 21.5 \mathrm{~Gy}$ to the mean ITV dose $\left(\mathrm{BED}=203 \mathrm{~Gy}_{10}\right)$. An additional set of dose objectives as shown in Table 1 was provided. This is based on an internal prestudy at the University Hospital of Zürich, which showed that this corresponds to a prescription of $3 \times 15 \mathrm{~Gy}$ to the $65 \%$ isodose for conformal treatment plans $\left(\mathrm{BED}=112 \mathrm{~Gy}_{10}\right)$, therefore fulfilling national and international guidelines (see supplemental material). No recommendations concerning dosecalculation algorithm, calculation-grid-size or MLC-leafwidth were given.

For OARs, the constraints from the DEGRO guidelines [22] were used. These were as low as reasonably achievable (ALARA) for the bilateral lungs, a dose to $0.1 \mathrm{ml}$ of the spinal canal below $18 \mathrm{~Gy}$ and the volume of the thoracic wall receiving $30 \mathrm{~Gy}$ or more below $30 \mathrm{ml}$.

\section{Analysis}

All plans were transferred into the MIM software (MIM software Inc., Cleveland, OH, USA) for analysis. The plans were divided into different categories depending on the SBRT technique used: robotic radiosurgery (RRS); modulated RT (MOD) including static intensity modulated therapy (IMRT) as well as intensity modulated arc therapy (IMAT); and 3D techniques (3D) including conformal arc (CA) as well as 3D conformal radiotherapy (3DRT). The planning systems and dose calculation algorithms were also evaluated. A dose-volume histogram (DVH) binning of $0.1 \mathrm{~Gy}$ was used for the evaluation in MIM.

For dosimetric evaluation of the ITV and PTV, the mean and median dose as well as the dose to $2 \%$ and $98 \%$ of the PTV were recorded according to the ICRU guidelines [14-17]. Furthermore, coverage of the ITV with the $90 \%$ and of the PTV with the $70 \%$ isodose were evaluated and the dose to $0.1 \mathrm{ml}$ of the PTV. To assess the conformity of the plans, two different conformity indices (CI) were used:
- The Radiation Therapy Oncology Group (RTOG) CI [24], which indicates the volume of healthy tissue relative to the PTV size exposed to the prescribed dose:

$\mathrm{CI}_{\mathrm{RTOG}}=\mathrm{V}(45.2 \mathrm{~Gy}) / \mathrm{V}_{\mathrm{PTV}}$

- The Paddick CI [25], which quantifies the high dose outside the tumor as well as the coverage of the tumor:

$$
\mathrm{CI}_{\text {Paddick }}=\mathrm{V}_{2 \mathrm{PTV}}(45.2 \mathrm{~Gy}) /\left(\mathrm{V}(45.2 \mathrm{~Gy}) \times \mathrm{V}_{\mathrm{PTV}}\right)
$$

Where $\mathrm{V}_{\mathrm{PTV}}$ is the volume of the PTV, $\mathrm{V}(45.2 \mathrm{~Gy})$ is the volume receiving at least $45.2 \mathrm{~Gy}$ and $\mathrm{V}_{\mathrm{PTV}}(45.2 \mathrm{~Gy})$ is the volume of the PTV receiving at least $45.2 \mathrm{~Gy}$.

To access the lower dose bath of the plans, the gradient index (GI) was also evaluated:

$\mathrm{GI}=\mathrm{V}(22.6 \mathrm{~Gy}) / \mathrm{V}(45.2 \mathrm{~Gy})$

The lungs (mean lung dose [MLF]) and thoracic wall (volume receiving minimally $30 \mathrm{~Gy}$ ) were evaluated as OARs. All other OAR were not relevant for these cases.

Kruskal-Wallis test implemented in MATLAB Version R2016a (The MathWorks Inc, Natick, MA, USA) was used to compare results for PTV, ITV and OAR parameters between different delivery techniques and algorithms used for dose calculation. Since the primary interest of this study was the difference in the mean PTV dose, no correction for multiple testing was applied for this variable. For all other parameters, statistics were corrected for multiple testing. $P$ values below 0.05 were considered significant.

\section{Results}

\section{Data collected}

A total of 57 SBRT plans from 27 institutions were analyzed in this study. These were 8 robotic radiosurgery (RRS, 14\%), 34 modulated plans (MOD, 60\%), and 15 3D confor-
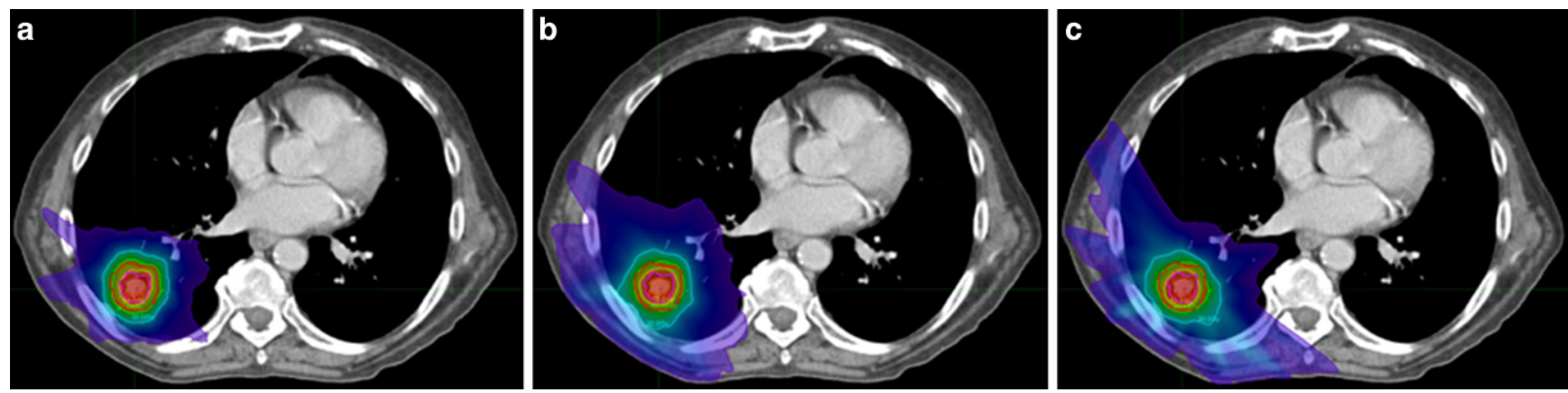

Fig. 2 Examples of dose distributions for the different techniques used in this planning study: a robotic radiosurgery (RSS), b modulated (MOD) and $\mathbf{c}$ 3D-conformal radiotherapy (3D) 
Fig. 3 Distribution of algorithms by different techniques used, robotic radiosurgery (RRS), modulated (MOD) and 3D-conformal radiotherapy (3D). Separation between Monte Carlo algorithms (MC), algorithms based on the Boltzmann transport equation (BT), collapsed cone algorithms (CC), analytical anisotropic algorithms (AAA) and pencil beam algorithms (PB). PB algorithms were excluded from the analysis

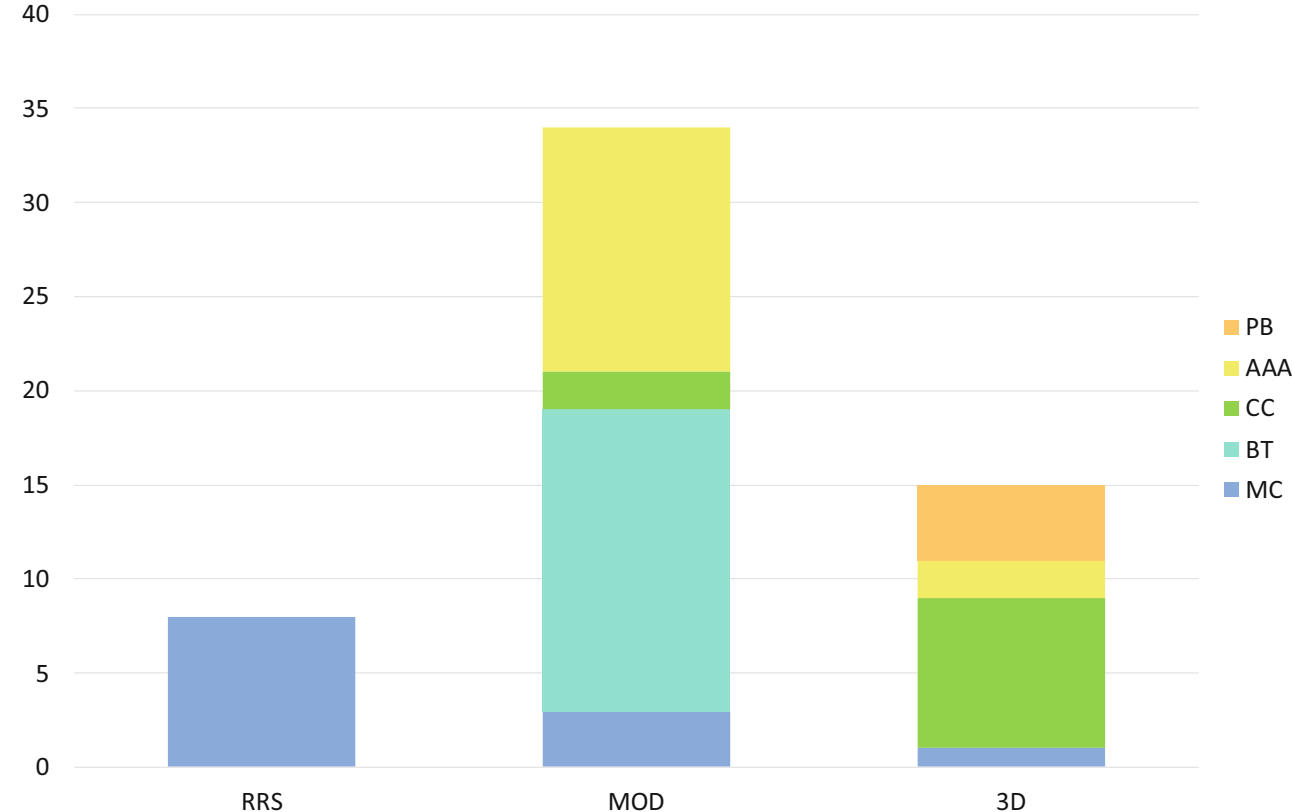

Table 2 Minor deviations from the planning objectives by different techniques and dose calculation algorithms

\begin{tabular}{llllllllll}
\hline Deviation & RRS & MOD & 3D & MC & BT & CC & AAA & PB & Total \\
\hline CI & 0 & 3 & 4 & 2 & 0 & 3 & 2 & 0 & 7 \\
D0.1 ml & 1 & 0 & 4 & 2 & 0 & 2 & 0 & 1 & 5 \\
PTV coverage & 0 & 3 & 0 & 0 & 2 & 0 & 1 & 0 & 3 \\
ITV coverage & 0 & 0 & 1 & 0 & 0 & 1 & 0 & 0 & 1 \\
\hline
\end{tabular}

$R R S$ robotic radiosurgery, $M O D$ modulated radiotherapy, 3D 3D-conformal radiotherapy, $M C$ Monte Carlo algorithm, $B T$ algorithms based on the Boltzmann transport equation, $C C$ collapsed cone algorithms, $A A A$ analytical anisotropic algorithms, $P B$ pencil beam algorithms, $C I$ conformity index, $D 0.1 \mathrm{ml}$ Dose to $0.1 \mathrm{ml}$, PTV planning target volume, ITV internal target volume

mal (3D) plans (26\%). Examples of the dose distribution for the different treatment techniques are shown in Fig. 2. Five different dose calculation algorithms were used; $21 \%$ of the plans were calculated with a Monte Carlo (MC) algorithm, $28 \%$ with an algorithm using the Boltzmann transport equation (BT), $17 \%$ used a collapsed cone (CC) algorithm, $26 \%$ the analytical anisotropy algorithm (AAA) and $7 \%$ a pencil beam algorithm (PB). The use of different dose calculation algorithms for the different treatment techniques is visualized in Fig. 3. Since usage of the PB does not comply with national and international guidelines [17, 19, 26, 27] these plans were discarded in the analysis. Results including these plans can be found in the supplemental material.

The multileaf collimator (MLC) width for the MLC Linac-based plans varied between $2.5 \mathrm{~mm}$ and $10 \mathrm{~mm}$ $(17 \times 2.5 \mathrm{~mm}, 2 \times 4 \mathrm{~mm}, 28 \times 5 \mathrm{~mm}, 2 \times 10 \mathrm{~mm})$. Most plans used either $6 \mathrm{MV}$ with flattening filter (FF; 37 plans) or flattening filter-free (FFF) beam (16 plans). Only 4 plans were created using $10 \mathrm{MV}$ FFF beams. It is also worth to notice that only one institution used an MLC with $1 \mathrm{~cm}$ leave width ( 2 plans), all others Linac-based plans used either $2.5 \mathrm{~mm}$ ( 17 plans), $4 \mathrm{~mm}$ ( 2 plans) or $5 \mathrm{~mm}$ leave width (28). All RRS plans were created using cones of different sizes with the minimal size being $12.5 \mathrm{~mm}$ ( 2 plans) or $15 \mathrm{~mm}$ (6 plans).

One MOD plan did not fulfill the constraints (too high conformity index) and was removed from the analysis. Another 18 cases showed a minor deviation. These minor deviations are summarized in Table 2.

Due to removal of plans calculated with PB and the one not fulfilling the constraints, 52 plans from 25 institutions were included in the final analysis.

\section{Characterization of the dose to the target volumes}

Different dosimetric parameters for the two patients and different treatment techniques are summarized in Table 3.

Due to the normalization, the mean ITV dose was identical in all cases and the median dose in the ITV varied only marginally (64.1-65.7 Gy for patient 1 and $64.2-65.4 \mathrm{~Gy}$ for patient 2). The median coverage of the ITV with the $90 \%$ isodose was above $99.1 \%(95.2-100 \%)$ for patient 1 and $98.5 \%$ (94.2-100\%) for patient 2. No significant difference 
Table 3 Results for the two patients and the different techniques. The plan which did not fulfill the constraint and the plans calculated with the pencil beam algorithm were excluded

\begin{tabular}{|c|c|c|c|c|c|c|c|}
\hline & & \multicolumn{3}{|l|}{ Patient 1} & \multicolumn{3}{|l|}{ Patient 2} \\
\hline & & RRS & MOD & $3 \mathrm{D}$ & RRS & MOD & $3 \mathrm{D}$ \\
\hline \multirow[t]{3}{*}{ ITV $D_{\text {median }}$} & Median & $65.0 \mathrm{~Gy}$ & $64.7 \mathrm{~Gy}$ & $65.0 \mathrm{~Gy}$ & $64.7 \mathrm{~Gy}$ & $64.6 \mathrm{~Gy}$ & $64.7 \mathrm{~Gy}$ \\
\hline & Mean & $65.1 \mathrm{~Gy}$ & $64.6 \mathrm{~Gy}$ & $64.9 \mathrm{~Gy}$ & $64.7 \mathrm{~Gy}$ & $64.7 \mathrm{~Gy}$ & $64.7 \mathrm{~Gy}$ \\
\hline & Std & $0.6 \mathrm{~Gy}$ & $0.2 \mathrm{~Gy}$ & $0.3 \mathrm{~Gy}$ & $0.3 \mathrm{~Gy}$ & $0.3 \mathrm{~Gy}$ & $0.2 \mathrm{~Gy}$ \\
\hline \multirow[t]{3}{*}{ ITV V90\% } & Median & $98.0 \%$ & $99.6 \%$ & 98.8 & $97.6 \%$ & $98.9 \%$ & $97.9 \%$ \\
\hline & Mean & $97.7 \%$ & $99.0 \%$ & $98.5 \%$ & $97.5 \%$ & $98.7 \%$ & $97.5 \%$ \\
\hline & Std & $1.9 \%$ & $1.1 \%$ & $0.9 \%$ & $1.7 \%$ & $1.2 \%$ & $2.3 \%$ \\
\hline \multirow[t]{3}{*}{ PTV D $D_{\text {mean }}$} & Median & $56.2 \mathrm{~Gy}$ & $56.9 \mathrm{~Gy}$ & $57.8 \mathrm{~Gy}$ & $55.6 \mathrm{~Gy}$ & $56.6 \mathrm{~Gy}$ & $57.2 \mathrm{~Gy}$ \\
\hline & Mean & $56.2 \mathrm{~Gy}$ & $56.9 \mathrm{~Gy}$ & $57.7 \mathrm{~Gy}$ & $55.7 \mathrm{~Gy}$ & $56.6 \mathrm{~Gy}$ & $57.0 \mathrm{~Gy}$ \\
\hline & Std & $0.6 \mathrm{~Gy}$ & $0.8 \mathrm{~Gy}$ & $0.7 \mathrm{~Gy}$ & $0.3 \mathrm{~Gy}$ & $0.5 \mathrm{~Gy}$ & $0.6 \mathrm{~Gy}$ \\
\hline \multirow[t]{3}{*}{ PTV D $D_{\text {median }}$} & Median & $55.7 \mathrm{~Gy}$ & $57.0 \mathrm{~Gy}$ & $58.8 \mathrm{~Gy}$ & $54.8 \mathrm{~Gy}$ & $56.5 \mathrm{~Gy}$ & $57.5 \mathrm{~Gy}$ \\
\hline & Mean & $55.5 \mathrm{~Gy}$ & $57.2 \mathrm{~Gy}$ & $58.4 \mathrm{~Gy}$ & $54.9 \mathrm{~Gy}$ & $56.7 \mathrm{~Gy}$ & $57.1 \mathrm{~Gy}$ \\
\hline & Std & $1.2 \mathrm{~Gy}$ & $1.2 \mathrm{~Gy}$ & $1.0 \mathrm{~Gy}$ & $0.4 \mathrm{~Gy}$ & $1.1 \mathrm{~Gy}$ & $1.0 \mathrm{~Gy}$ \\
\hline \multirow[t]{3}{*}{ PTV V70\% } & Median & $97.8 \%$ & $96.6 \%$ & $96.2 \%$ & $96.2 \%$ & $95.9 \%$ & $95.9 \%$ \\
\hline & Mean & $97.6 \%$ & $97.0 \%$ & $96.4 \%$ & $96.4 \%$ & $95.7 \%$ & $96.9 \%$ \\
\hline & Std & $2.1 \%$ & $1.7 \%$ & $0.7 \%$ & $0.8 \%$ & $2.4 \%$ & $0.8 \%$ \\
\hline \multirow[t]{3}{*}{ D0.1 ml } & Median & $68.6 \mathrm{~Gy}$ & $67.7 \mathrm{~Gy}$ & $67.8 \mathrm{~Gy}$ & $68.9 \mathrm{~Gy}$ & $67.5 \mathrm{~Gy}$ & 69.4Gy \\
\hline & Mean & $68.7 \mathrm{~Gy}$ & $67.6 \mathrm{~Gy}$ & $67.8 \mathrm{~Gy}$ & 69.1 Gy & $67.8 \mathrm{~Gy}$ & $69.3 \mathrm{~Gy}$ \\
\hline & Std & $0.7 \mathrm{~Gy}$ & $1.1 \mathrm{~Gy}$ & $0.4 \mathrm{~Gy}$ & $0.6 \mathrm{~Gy}$ & $1.0 \mathrm{~Gy}$ & $0.5 \mathrm{~Gy}$ \\
\hline \multirow[t]{3}{*}{ PTV D2\% } & Median & $67.9 \mathrm{~Gy}$ & $67.1 \mathrm{~Gy}$ & $67.3 \mathrm{~Gy}$ & $68.3 \mathrm{~Gy}$ & $67.4 \mathrm{~Gy}$ & $68.8 \mathrm{~Gy}$ \\
\hline & Mean & $67.8 \mathrm{~Gy}$ & $66.9 \mathrm{~Gy}$ & $67.2 \mathrm{~Gy}$ & $68.6 \mathrm{~Gy}$ & $67.3 \mathrm{~Gy}$ & $68.6 \mathrm{~Gy}$ \\
\hline & Std & $0.6 \mathrm{~Gy}$ & $0.8 \mathrm{~Gy}$ & $0.3 \mathrm{~Gy}$ & $0.7 \mathrm{~Gy}$ & $0.8 \mathrm{~Gy}$ & $0.4 \mathrm{~Gy}$ \\
\hline \multirow[t]{3}{*}{ PTV D98\% } & Median & $45.0 \mathrm{~Gy}$ & $44.2 \mathrm{~Gy}$ & $43.8 \mathrm{~Gy}$ & $44.2 \mathrm{~Gy}$ & $44.0 \mathrm{~Gy}$ & $43.2 \mathrm{~Gy}$ \\
\hline & Mean & $44.6 \mathrm{~Gy}$ & 43.9 Gy & 43.6 Gy & $44.2 \mathrm{~Gy}$ & $43.2 \mathrm{~Gy}$ & 43.4 Gy \\
\hline & Std & $1.6 \mathrm{~Gy}$ & $3.1 \mathrm{~Gy}$ & $0.4 \mathrm{~Gy}$ & $0.5 \mathrm{~Gy}$ & $3.2 \mathrm{~Gy}$ & $0.9 \mathrm{~Gy}$ \\
\hline \multirow[t]{3}{*}{ PTV CI RTOG } & Median & 1.13 & 1.14 & 1.20 & 1.11 & 1.12 & 1.20 \\
\hline & Mean & 1.13 & 1.13 & 1.18 & 1.10 & 1.12 & 1.20 \\
\hline & Std & 0.04 & 0.07 & 0.04 & 0.05 & 0.05 & 0.04 \\
\hline \multirow[t]{3}{*}{ PTV CIPaddick } & Median & 0.85 & 0.84 & 0.78 & 0.84 & 0.83 & 0.77 \\
\hline & Mean & 0.85 & 0.83 & 0.78 & 0.85 & 0.82 & 0.77 \\
\hline & Std & 0.02 & 0.05 & 0.02 & 0.03 & 0.05 & 0.03 \\
\hline \multirow[t]{3}{*}{ PTV GI } & Median & 3.76 & 4.21 & 4.13 & 3.93 & 4.22 & 4.46 \\
\hline & Mean & 4.03 & 4.14 & 4.51 & 4.03 & 4.34 & 4.77 \\
\hline & Std & 0.77 & 0.31 & 1.07 & 0.53 & 0.49 & 1.14 \\
\hline \multirow{3}{*}{$\begin{array}{l}\text { Ipsilateral lung } \\
\mathrm{D}_{\text {mean }}\end{array}$} & Median & $5.8 \mathrm{~Gy}$ & $5.4 \mathrm{~Gy}$ & $5.8 \mathrm{~Gy}$ & $4.2 \mathrm{~Gy}$ & $3.4 \mathrm{~Gy}$ & $3.5 \mathrm{~Gy}$ \\
\hline & Mean & $6 \mathrm{~Gy}$ & $5.4 \mathrm{~Gy}$ & $5.6 \mathrm{~Gy}$ & 4.1 Gy & $3.5 \mathrm{~Gy}$ & $3.5 \mathrm{~Gy}$ \\
\hline & Std & $0.4 \mathrm{~Gy}$ & $0.5 \mathrm{~Gy}$ & $0.3 \mathrm{~Gy}$ & $0.3 \mathrm{~Gy}$ & $0.5 \mathrm{~Gy}$ & $0.3 \mathrm{~Gy}$ \\
\hline \multirow{3}{*}{$\begin{array}{l}\text { Contralateral } \\
\text { lung } \mathrm{D}_{\text {mean }}\end{array}$} & Median & $1.0 \mathrm{~Gy}$ & $0.8 \mathrm{~Gy}$ & $0.7 \mathrm{~Gy}$ & $0.7 \mathrm{~Gy}$ & $0.6 \mathrm{~Gy}$ & $0.6 \mathrm{~Gy}$ \\
\hline & Mean & $1.0 \mathrm{~Gy}$ & $0.8 \mathrm{~Gy}$ & $0.8 \mathrm{~Gy}$ & $0.7 \mathrm{~Gy}$ & $0.6 \mathrm{~Gy}$ & $0.6 \mathrm{~Gy}$ \\
\hline & Std & $0.2 \mathrm{~Gy}$ & $0.1 \mathrm{~Gy}$ & $0.1 \mathrm{~Gy}$ & $0.2 \mathrm{~Gy}$ & $0.2 \mathrm{~Gy}$ & $0.1 \mathrm{~Gy}$ \\
\hline \multirow{3}{*}{$\begin{array}{l}\text { Thoracic wall } \\
\text { V30Gy }\end{array}$} & Median & $7.2 \mathrm{ml}$ & $7.3 \mathrm{ml}$ & $7.6 \mathrm{ml}$ & - & - & - \\
\hline & Mean & $7.3 \mathrm{ml}$ & $7.3 \mathrm{ml}$ & $7.6 \mathrm{ml}$ & - & - & - \\
\hline & Std & $1.5 \mathrm{ml}$ & $0.7 \mathrm{ml}$ & $0 . \mathrm{ml}$ & - & - & - \\
\hline
\end{tabular}

$R R S$ robotic radiosurgery, $M O D$ modulated radiotherapy, 3D 3D-conformal radiotherapy, ITV internal target volume, $V x \%$ volume recieving $\mathrm{x} \%$ of the prescribed dose, $P T V$ planning target volume, Dx\% Dose to $\mathrm{x} \%$ of the volume, $C I$ conformity index, $G I$ gradient index 

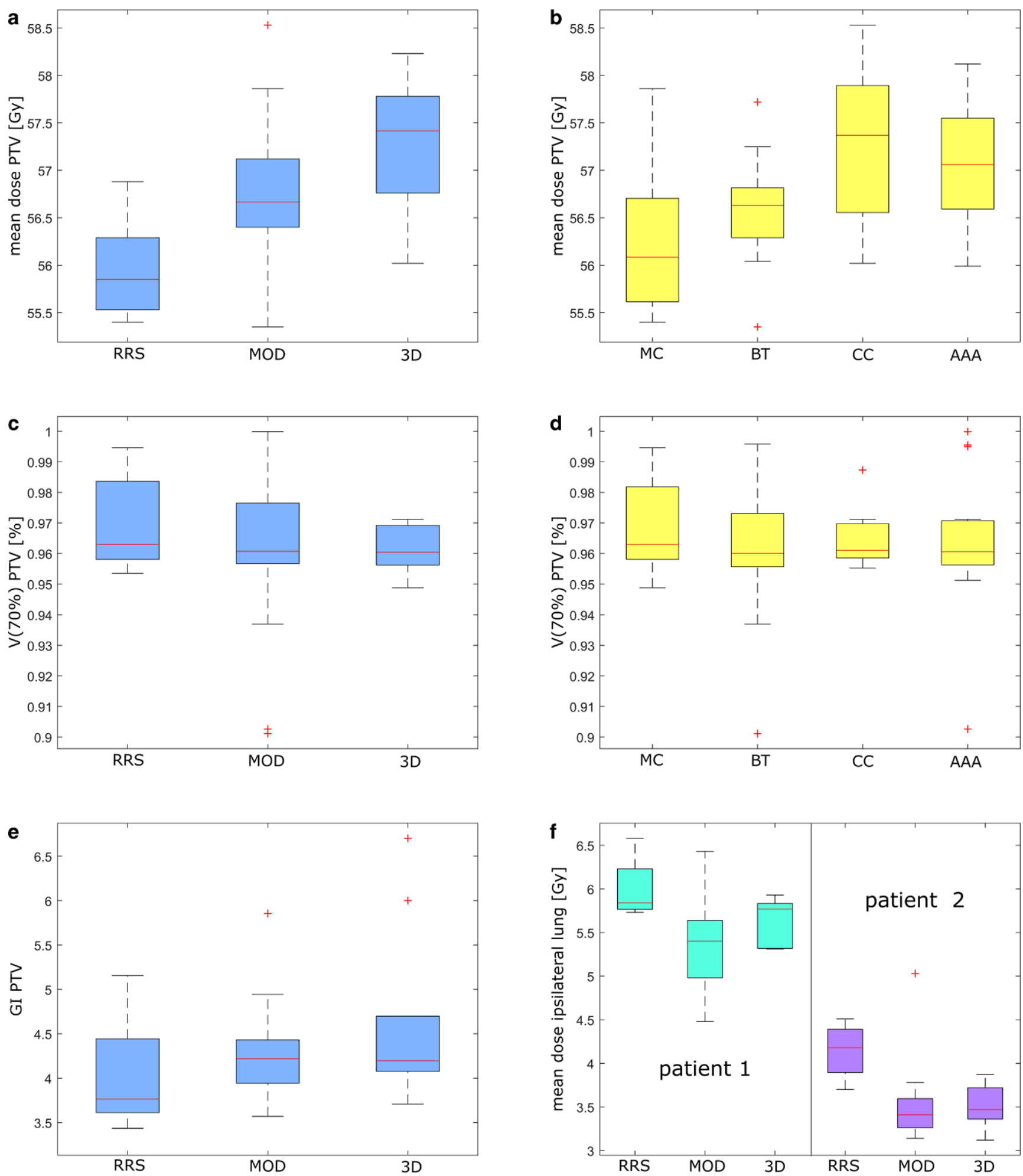

Fig. 4 a, b The mean planning target volume (PTV) dose; c, $\mathbf{d}$ the coverage of the PTV with the $70 \%$ (= 45.2 Gy) isodose V(70\%) for different treatment techniques and dose calculation algorithms (Monte Carlo algorithm [MC], algorithms based on the Boltzmann transport equation [BT], collapsed cone algorithms [CC] and analytical anisotropic algorithms [AAA]), respectively. e The gradient index (GI) and $\mathbf{f}$ the mean dose to the ipsilateral lung for different treatment techniques (robotic radiosurgery [RRS], modulated radiotherapy [MOD] and 3D-conformal radiotherapy $[3 \mathrm{D}])$. The plan which did not fulfill the constraint and the plans calculated with the pencil beam algorithm were excluded 
between SBRT techniques or dose calculation algorithms was observed.

The distributions of the mean PTV dose did not differ significantly between the two patients (median $56.9 \mathrm{~Gy}$ vs $56.6 \mathrm{~Gy}$ ). There was a significant but small difference between the techniques $(p<0.01)$, with RRS having the lowest mean PTV dose with median 55.9 Gy (range 55.4-56.9 Gy) followed by MOD plans with 56.6 Gy (55.4-58.5 Gy) and $3 \mathrm{D}$ plans characterized by the highest dose with $57.4 \mathrm{~Gy}$ (56.0-58.1 Gy) as shown in Fig. 4a. Difference between dose calculation algorithms was also significant $(p=0.01)$ with highest PTV doses observed for the CC algorithm and lowest for the MC algorithm (Fig. 4b). The median dose to the PTV showed a very similar pattern.

The coverage of the PTV with the $70 \%$ isodose (=45.2 Gy) showed no significant variation between the techniques and algorithms as shown in Fig. 4c,d. However, there was some residual interinstitutional variation (median $96.1 \%$, range $90-100 \%$ ), with four plans being below $95 \%$ coverage (3 MOD plans and $13 \mathrm{D}$ plan).

Doses to $0.1 \mathrm{ml}, 2 \%$ and $98 \%$ of the PTV were comparable between the different techniques and algorithms. Regarding D98\% there were 3 outliers to lower dose values, 1 for patient 1 (32.6Gy [MOD, AAA]) and 2 for patient 2 (32.6 Gy [MOD, AAA] and 39.4Gy [MOD, BT]). The lowest values for each patient originated from the same institution.

There was no significant interinstitutional or intertechnology variability regarding the conformity indices (Table 3 ) or gradient index. However, the GI showed considerable interinstitutional variation (median 4.2, range 3.4-6.7). An example of the difference in the $22.6 \mathrm{~Gy}$ isodose line used for the GI can be found in the supplemental material.

\section{Characterization of the dose to the OAR}

No significant difference between the techniques were observed for the OARs. The median of the mean dose to the ipsilateral lung was 5.8Gy (RRS), 5.4Gy (MOD) and 5.8 Gy (3D) for patient 1 and 4.2 Gy (RRS), 3.4 Gy (MOD) and $3.5 \mathrm{~Gy}$ (3D) for patient 2 (Fig. 4f). However, while there was no significant difference between the algorithms for patient 1 , there was one for patient $2(p=0.03), \mathrm{MC}$ algorithms calculated the highest dose, while AAA algorithms suggested the lowest dose in the ipsilateral lung.

The contralateral lung only received very low doses, median $0.8 \mathrm{~Gy}$ (range $0.6-1.2 \mathrm{~Gy}$ ) for patient 1 and median $0.6 \mathrm{~Gy}$ (range $0.5-1.2 \mathrm{~Gy}$ ) for patient 2 . For patient 1 the volume of the thoracic wall receiving $30 \mathrm{~Gy}$ was $7.3 \mathrm{ml}$ with a range of 5.6-9.2 ml. For patient 2 the PTV was distant to the thoracic wall such that maximum doses were below $30 \mathrm{~Gy}$.

\section{Discussion}

SBRT is used widely for primary lung tumors such as NSCLC as well as for pulmonary oligometastatic disease [2-4, 9, 28]. Recommendations for these treatments exist from different organizations [19, 22, 26, 29]. However, even following these, significant differences between studies, institutions and SBRT techniques for doses to target volumes as well as OAR have been published [13, 18, 30, 31].

In the current study, dose prescription to the mean ITV dose combined with additional ITV- and PTV-based planning objectives achieved highly consistent dose distributions within the target volume. Mean and median dose to the PTV varied by less than $3 \%$ of the prescribed dose, which is of the order of magnitude as treatment planning for a static phantom [26, 32]. This high consistency was achieved despite the large number of participating institutions ( $n=27)$, the use of heterogeneous planning techniques and planning for all currently available SBRT delivery platforms. We are therefore convinced that the proposed pulmonary SBRT planning and dose prescription methodology is generalizable.

We believe that in particular the use of several DVHbased planning objectives for the ITV and PTV contributed to homogenize dose distribution between centers. Unfortunately, the ICRU Report 91 for stereotactic treatments [17] still recommends only to prescribe to one single DVH point of the PTV and does not give any additional objectives for GTV, CTV or ITV as already discussed in [33]. However, it recommends reporting multiple dose parameters for GTV, CTV, ITV and PTV to make treatment outcome more comparable.

The recent study evaluating the difference in dose to GTV and PTV of multiple centers [20] concluded that a multiparametric prescription is needed. The study suggests as minimum requirement a BED10 of $150 \mathrm{~Gy}$ as mean ITV dose. However, our study showed that even a higher dose to the ITV is possible.

The single SBRT plan with an inacceptable deviation in $\mathrm{CI}$ and 4 plans out of 7 with minor deviations for the CI were observed for one specific planning system. This demonstrates the general problem that volume calculation and also the display of contours and dose may differ significantly between planning systems depending on how calculation voxels are then interpolated. In all cases the planning institution assumed to fulfill the planning objectives when plan evaluation was performed in the respective planning system. This clearly indicates the need that vendors agree on one common way to interpret partial volume effects between voxels and DICOM structures. The other three minor deviations for the conformity index showed no particular pattern and originated from different planning systems. Four out of five minor deviations of the dose to $0.1 \mathrm{ml}$ of 
the PTV were planned with a 3D static field technique. Using 3D conformal forward planning, it is obviously more difficult to simultaneously control all parameters. Similarly, no pattern was observed for the deviations in ITV and PTV coverage.

All OAR constraints OAR were fulfilled by all institutions and by all SBRT plans for both patients. All institutions followed the ALARA principle and achieved very similar results of OAR sparing, irrespective of the SBRT planning and delivery technique.

The significant difference in the ipsilateral mean lung dose as a function of algorithm is interesting. Nevertheless, they might have to be allocated to the fact that for RRS only MC was used for the dose calculation while for MOD treatments, BT and AAA dominate and for the 3D treatment plans, $\mathrm{CC}$ dominates. Even though the deviations we see are small, according to ICRU 91 and other recommendations $[17,26,29]$ a type B or MC algorithm, which takes into account the lateral electron scattering in inhomogeneous media, should be used for SBRT, in particular in the lung. In addition, the abovementioned recommendations suggest the use of a calculation grid of $2 \mathrm{~mm}$ or smaller, but for 13 plans a calculation grid of $2.5 \mathrm{~mm}$, for 5 plans a calculation grid of $3 \mathrm{~mm}$ and for 3 plans a calculation grid of as large as $4 \mathrm{~mm}$ was used. In particular the use of a calculation grid larger than $3 \mathrm{~mm}$ should be avoided; however, nowadays with sufficient computing power, grid sizes of $2 \mathrm{~mm}$ should be feasible in daily routine practice.

Possibly, part of the deviations which were accepted by the planner, could be omitted if regular knowledgeexchange and training was performed on national and international level. This is in line with a survey on the Influence of Institutional Experience and Technological Advances on Outcome of Stereotactic Body Radiation Therapy for Oligometastatic Lung Disease [34] which showed a relation between the local control and the experience of the center, as well as with a recent review on dosimetric multicenter planning comparison studies for SBRT [35] and two other multicentric planning studies for spine SBRT and prostate SBRT [36, 37].

One of the limitations of this study is that only two patients were evaluated which are not representative for all patients. We added to the supplemental material a further study containing 40 patients, where we evaluated the optimal constraints for the planning study in order to have minimal variation in different dosimetric parameters between the different patients. However, these were only planned by one single institution. Therefore, conclusions drawn from this study should be evaluated on more patients in a multicenter setting.

A further limitation is the fact that motion management of different institutions was not evaluated. Nevertheless, a recent detailed 4D dose analysis has indicated negligible difference and variability of GTV mean and near minimum dose between ITV-based and mid-ventilation-based PTV optimization and GTV-based robust optimization provided that normalization is done to the GTV mean dose [38]. Using different motion management strategies might have resulted in smaller doses to the OAR as for this study the target contours were delineated based on an ITV concept. Furthermore, this study relies on the correct dose calculation of the plans, independent from the treatment algorithm used and no dosimetric evaluation of the applicability of the plans was performed. Additionally, the dose to the ITV and not to the GTV was reported in our study, as this would require a full $4 \mathrm{D}$ dose calculation taking the range of motion into account; however, it has been shown that there is very close association between mean ITV and GTV dose despite large interpatient variations in GTV volume and motion range [39-41]. In the cases where no ITV was defined due to a different motion management, prescribing to the mean dose to the GTV might thus be equivalent to prescribing to the mean ITV dose as used in this study while prescribing to the mean PTV dose might not be the optimal strategy.

We evaluated the study according to the recently published Radiotherapy Treatment plannINg study Guidelines (RATING) [42] and achieved a score of 166 out of 186 points $(89 \%)$, even though the study was conducted before these guidelines had been published.

\section{Conclusions}

Analyzing 52 plans from 25 institutions, this planning study demonstrated that dose prescription to the mean internal target volume (ITV) dose in combination with detailed dose-volume histogram (DVH)-based planning objectives for planning target volume (PTV) and ITV achieves highly consistent dose distributions irrespective of the planning institution, and the stereotactic body radiotherapy (SBRT) planning and delivery technologies. We therefore recommend to evaluate the proposed planning approach.

Supplementary Information The online version of this article (https:// doi.org/10.1007/s00066-021-01799-w) contains supplementary material, which is available to authorized users.

Funding Open Access funding provided by Universität Zürich.

Conflict of interest L. Wilke, C. Moustakis, O. Blanck, D. Albers, C. Albrecht, Y. Avcu, R. Boucenna, K. Buchauer, T. Etzelstorfer, C. Henkenberens, D. Jeller, K. Jurianz, C. Kornhuber, M. Kretschmer, S. Lotze, K. Meier, P. Pemler, A. Riegler, A. Röser, D. Schmidhalter, K.H. Spruijt, G. Surber, V. Vallet, R. Wiehle, J. Willner, P. Winkler, A. Wittig, M. Guckenberger and S. Tanadini-Lang declare that they have no competing interests.

Open Access This article is licensed under a Creative Commons Attribution 4.0 International License, which permits use, sharing, adapta- 
tion, distribution and reproduction in any medium or format, as long as you give appropriate credit to the original author(s) and the source, provide a link to the Creative Commons licence, and indicate if changes were made. The images or other third party material in this article are included in the article's Creative Commons licence, unless indicated otherwise in a credit line to the material. If material is not included in the article's Creative Commons licence and your intended use is not permitted by statutory regulation or exceeds the permitted use, you will need to obtain permission directly from the copyright holder. To view a copy of this licence, visit http://creativecommons.org/licenses/by/4. $0 /$.

\section{References}

1. Raz DJ, Zell JA, Ou SI et al (2007) Natural history of stage I non-small cell lung cancer: implications for early detection. Chest 132(1):193-199

2. Rocco G, Morabito A, Leone A et al (2016) Management of nonsmall cell lung cancer in the era of personalized medicine. Int $\mathbf{J}$ Biochem Cell Biol 78:173-179

3. Chang JY, Senan S, Paul MA et al (2015) Stereotactic ablative radiotherapy versus lobectomy for operable stage I non-small-cell lung cancer: a pooled analysis of two randomised trials. Lancet Oncol 16(6):630-637

4. Guckenberger M, Allgäuer M, Appold S et al (2013) Safety and efficacy of stereotactic body radiotherapy for stage I non-smallcell lung cancer in routine clinical practice: a patterns-of-care and outcome analysis. J Thorac Oncol 8(8):1050-1058

5. Maquilan G, Timmerman R (2016) Stereotactic body radiation therapy for early-stage lung cancer. Cancer J 22(4):274-279. https:// doi.org/10.1097/ppo.0000000000000204

6. Collen C, Christian N, Schallier D et al (2014) Phase II study of stereotactic body radiotherapy to primary tumor and metastatic locations in oligometastatic nonsmall-cell lung cancer patients. Ann Oncol 25(10): 1954-1959

7. Guckenberger M, Klement RJ, Allgäuer M et al (2016) Local tumor control probability modeling of primary and secondary lung tumors in stereotactic body radiotherapy. Radiother Oncol 118(3):485-491

8. Iyengar P, Kavanagh BD, Wardak Z et al (2014) Phase II trial of stereotactic body radiation therapy combined with erlotinib for patients with limited but progressive metastatic non-small-cell lung cancer. J Clin Oncol 32(34):3824-3830

9. Rieber J, Streblow J, Uhlmann L et al (2016) Stereotactic body radiotherapy (SBRT) for medically inoperable lung metastases-A pooled analysis of the German working group "stereotactic radiotherapy”. J Lung Cancer 97:51-58

10. Rusthoven KE, Kavanagh BD, Burri SH et al (2009) Multi-institutional phase I/II trial of stereotactic body radiation therapy for lung metastases. J Clin Oncol 27(10):1579-1584

11. Tanadini-Lang S, Rieber J, Filippi AR et al (2017) Nomogram based overall survival prediction in stereotactic body radiotherapy for oligo-metastatic lung disease. Radiother Oncol 123(2):182-188

12. Klement RJ, Allgäuer M, Andratschke N et al (2016) Bayesian cure rate modeling of local tumor control: evaluation in stereotactic body radiation therapy for pulmonary metastases. Int J Radiat Oncol Biol Phys 94(4):841-849

13. Giglioli FR, Strigari L, Ragona R et al (2016) Lung stereotactic ablative body radiotherapy: a large scale multi-institutional planning comparison for interpreting results of multi-institutional studies. Phys Med 32(4):600-606

14. Landberg T, Chavaudra J, Dobbs J et al (2016) Report 50. J Int Comm Radiat Units Meas. https://doi.org/10.1093/jicru/os26.1. Report50
15. Landberg T, Chavaudra J, Dobbs J et al (2016) Report 62. J Int Comm Radiat Units Meas. https://doi.org/10.1093/jicru/os32.1. Report62

16. Units ICoR, Measurements (2010) ICRU report 83 prescribing, recording, and reporting photon-beam intensity-modulated radiation therapy (IMRT). J ICRU 10(1):1-3

17. Seuntjens S, Lartigau E, Cora $S$ et al (2014) ICRU report 91. Prescribing, recording, and reporting of stereotactic treatments with small photon beams. J ICRU 14(2):101-109

18. Moustakis C, Blanck O, Tazehmahalleh FE et al (2017) Planning benchmark study for SBRT of early stage NSCLC. Strahlenther Onkol 193(10):780-790

19. Guckenberger M, Andratschke N, Dieckmann K et al (2017) ESTRO ACROP consensus guideline on implementation and practice of stereotactic body radiotherapy for peripherally located early stage non-small cell lung cancer. Radiother Oncol 124(1):11-17

20. de Jong EEC, Guckenberger M, Andratschke N et al (2020) Variation in current prescription practice of stereotactic body radiotherapy for peripherally located early stage non-small cell lung cancer: Recommendations for prescribing and recording according to the ACROP guideline and ICRU report 91. Radiother Oncol 142:217-223. https://doi.org/10.1016/j.radonc.2019.11.001

21. Baumann R, Chan MK, Pyschny F et al (2018) Clinical results of mean GTV dose optimized robotic-guided stereotactic body radiation therapy for lung tumors. Front Oncol 8:171

22. Guckenberger M, Andratschke N, Alheit H et al (2014) Definition of stereotactic body radiotherapy. Strahlenther Onkol 190(1):26-33

23. Klement RJ, Sonke J-J, Allgäuer M et al (2020) Correlating dose variables with local tumor control in stereotactic body radiotherapy for early stage non-small cell lung cancer: A modelling study on 1500 individual treatments. Int J Radiat Oncol Biol Phys 107(3):579-586. https://doi.org/10.1016/j.ijrobp.2020.03.005

24. Feuvret L, Noël G, Mazeron J-J et al (2006) Conformity index: a review. Int J Radiat Oncol Biol Phys 64(2):333-342

25. Paddick I (2000) A simple scoring ratio to index the conformity of radiosurgical treatment plans. J Neurosurg 93(Suppl 3):219-222

26. Benedict SH, Yenice KM, Followill D et al (2010) Stereotactic body radiation therapy: the report of AAPM Task Group 101. Med Phys 37(8):4078-4101

27. Guckenberger M, Baus WW, Blanck O et al (2020) Definition and quality requirements for stereotactic radiotherapy: consensus statement from the DEGRO/DGMP Working Group Stereotactic Radiotherapy and Radiosurgery. Strahlenther Onkol 196(5):417-420. https://doi.org/10.1007/s00066-020-01603-1

28. Guckenberger M (2015) Oligoprogression. Strahlenther Onkol 191(5):453-455

29. SABR UK Consortium (2019) Stereotactic Ablative Body Radiation therapy (SABR): A resource. The Royal College of Radiologists,

30. Ong CL, Verbakel WF, Cuijpers JP et al (2010) Stereotactic radiotherapy for peripheral lung tumors: a comparison of volumetric modulated arc therapy with 3 other delivery techniques. Radiother Oncol 97(3):437-442

31. Weyh A, Konski A, Nalichowski A et al (2013) Lung SBRT: dosimetric and delivery comparison of RapidArc, TomoTherapy, and IMRT. J Appl Clin Med Phys 14(4):3-13

32. Seppala J, Suilamo S, Kulmala J et al (2012) A dosimetric phantom study of dose accuracy and build-up effects using IMRT and RapidArc in stereotactic irradiation of lung tumours. Radiat Oncol 7(1):79

33. Wilke L, Andratschke N, Blanck O et al (2019) ICRU report 91 on prescribing, recording, and reporting of stereotactic treatments with small photon beams. Strahlenther Onkol 195(3):193-198

34. Rieber J, Abbassi-Senger N, Adebahr S et al (2017) Influence of institutional experience and technological advances on outcome of 
stereotactic body radiation therapy for oligometastatic lung disease. Int J Radiat Oncol Biol Phys 98(3):511-520

35. Giglioli FR, Garibaldi C, Blanck O et al (2020) Dosimetric multicenter planning comparison studies for stereotactic body radiation therapy: methodology and future perspectives. Int J Radiat Oncol Biol Phys 106(2):403-412. https://doi.org/10.1016/j.ijrobp.2019. 10.041

36. Esposito M, Masi L, Zani M et al (2019) SBRT planning for spinal metastasis: indications from a large multicentric study. Strahlenther Onkol 195(3):226-235. https://doi.org/10.1007/s00066-018-13832

37. Villaggi E, Hernandez V, Fusella M et al (2019) Plan quality improvement by DVH sharing and planner's experience: Results of a SBRT multicentric planning study on prostate. Phys Med 62:73-82. https://doi.org/10.1016/j.ejmp.2019.05.003

38. Leung RWK, Chan MKH, Chiang CL et al (2020) On the pitfalls of PTV in lung SBRT using type-B dose engine: an analysis of PTV and worst case scenario concepts for treatment plan optimization. Radiat Oncol 15(1):130. https://doi.org/10.1186/s13014-02001573-9
39. Ehrbar S, Jöhl A, Tartas A et al (2017) ITV, mid-ventilation, gating or couch tracking - A comparison of respiratory motion-management techniques based on 4D dose calculations. Radiother Oncol 124(1):80-88. https://doi.org/10.1016/j.radonc.2017.05.016

40. Ehrbar S, Perrin R, Peroni M et al (2016) Respiratory motionmanagement in stereotactic body radiation therapy for lung cancer-A dosimetric comparison in an anthropomorphic lung phantom (LuCa). Radiother Oncol 121(2):328-334. https://doi.org/10. 1016/j.radonc.2016.10.011

41. Guckenberger M, Wilbert J, Krieger T et al (2007) Four-dimensional treatment planning for stereotactic body radiotherapy. Int $\mathrm{J}$ Radiat Oncol Biol Phys 69(1):276-285. https://doi.org/10.1016/j. ijrobp.2007.04.074

42. Hansen CR, Crijns W, Hussein M et al (2020) Radiotherapy Treatment plannINg study Guidelines (RATING): a framework for setting up and reporting on scientific treatment planning studies. Radiother Oncol 153:67-78. https://doi.org/10.1016/j.radonc.2020. 09.033 